\title{
VIP: A New Promising Marker for AECOPD - A Fashionable Marker Soon Forgotten?
}

\author{
Giovanna Elisiana Carpagnano ${ }^{a}$ Girolamo Pelaia $^{\mathrm{b}}$ \\ ${ }^{a}$ Respiratory Diseases Section, Medical and Surgical Sciences Department, University of Foggia, Foggia, and \\ ${ }^{\mathrm{b}}$ Respiratory Diseases Section, Medical and Surgical Sciences Department, University of Catanzaro, Catanzaro, Italy
}

It is almost impossible to discuss chronic obstructive pulmonary disease (COPD) without making reference to phenotypes or endotypes. Among COPD phenotypes, there is one which is widely recognized for its clinical and economic implications. This is characterized by a high susceptibility to experience acute exacerbations of chronic obstructive pulmonary disease (AECOPD). AECOPD are natural events occurring in the course of COPD, but still remain a major cause of morbidity and mortality associated with this disease [1]. Clinical criteria that define an acute exacerbation are subjective and open for debate. Hence, it is necessary to identify reliable biomarkers that could help in the early identification of AECOPD, also allowing their clinical progression to be measured. This is especially the case when considering the unfavorable outcomes and the socioeconomic costs that acute exacerbations of the disease predict. Several circulating markers are commonly used in clinical practice for the study of patients with AECOPD, such as white blood count (WBC), C-reactive protein (CRP) and erythrocyte sedimentation rate (ESR), although these are nonspecific and not particularly sensitive $[2,3]$. Furthermore, these clinically available markers are not useful in the early identification of AECOPD, and are therefore not effective in reducing the progression of the disease. Some reports are also available, referring to other new possible markers of AECOPD, such as neutrophil-lymphocyte ratio (NLR) (c) 2015 S. Karger AG, Basel

0025-7931/15/0905-0353\$39.50/0 and copeptin $[1,4]$. Procalcitonin (PCT) has also been proposed as a fashionable marker for AECOPD, although most experts agree that it is not reliable in predicting bacterial infections in AECOPD [5].

In this issue of Respiration, Mandal et al. [6] report the results of their very interesting study about vasoactive intestinal peptide (VIP), properly investigated by these authors and proposed as a promising marker for AECOPD. Indeed, an increased VIP immunoreactivity has been previously found in the airway epithelium and bronchial glands of COPD patients, in comparison to smokers with normal lung function [7]. But are we witnessing the birth of a new clinical tool for the early identification of acute exacerbations of COPD, or will this be the usual fashionable marker that will result in a few publications, but will then be soon forgotten?

The authors of the study detected higher circulating levels of VIP in subjects with AECOPD, when compared to stable COPD patients, and identified a cutoff of $88 \mathrm{pg} /$ $\mathrm{ml}$ that could be clinically useful as an indicator of exacerbation. We acknowledge that the results of this study are very stimulating, but we have some questions about the potentiality of VIP as a reliable marker of AECOPD. First, notwithstanding the authors' declaration of a robust performance of VIP in AECOPD diagnosis, how can a single marker be able to identify such different diseases as arthritis, diabetes, cancer, bowel diseases, heart failure,
Giovanna Elisiana Carpagnano

Respiratory Diseases Section, Medical and Surgical Sciences Department University of Foggia IT-70121 Foggia (Italy)

E-Mail ge.carpagnano@unifg.it 
atopic dermatitis and rhinitis [8-12]? The high specificity of VIP in AECOPD diagnosis reported by the authors refers to a small population of 120 COPD patients with acute disease exacerbations, and we believe the study requires at least a solid confirmation on larger patient populations, possibly to be investigated by multidisciplinary studies. A second question is whether VIP would be validated in the near future, and its dosage standardized in clinical practice.
Finally, we recognize that no single biomarker in COPD, as in all other human diseases, is enough to provide a wide acceptance of clinical information. Therefore, we suggest that there is an urgent need to identify a panel of potential biomarkers, such as VIP, which in combination may increase the singular power of each, thus being potentially useful for AECOPD in clinical practice, in order to allow early recognition of this condition, and also to monitor the effects of treatment.

\section{References}

1 Antonescu-Turcu AL, Tomic R: C-reactive protein and copeptin: prognostic predictors in chronic obstructive pulmonary disease exacerbations. Curr Opin Pulm Med 2009;15: 120-125.

$\checkmark 2$ Patel AR, Hurst JR, Wedzicha JA: The potential value of biomarkers in diagnosis and staging of COPD and exacerbations. Semin Respir Crit Care Med 2010;31:267-275.

-3 Rosenberg SR, Kalhan R: Biomarkers in chronic obstructive pulmonary disease. Transl Res 2012;159:228-237.

4 Taylan M, Demir M, Kaya H, Selimoglu Sen H, Abakay O, Carkanat Aİ, Abakay A, Tanrikulu AC, Sezgi C: Alterations of the neutrophil-lymphocyte ratio during the period of stable and acute exacerbation of chronic obstructive pulmonary disease patients. Clin Respir J, DOI: 10.1111/crj.12336.

5 Daniels JM, Schoorl M, Snijders D, Knol DL, Lutter R, Jansen HM, Boersma WG: Procalci- tonin versus C-reactive protein as predictive markers of response to antibiotic therapy in acute exacerbations of COPD. Chest 2010; 138:1108-1115.

6 Mandal J, Roth M, Costa L, Boeck L, Rakic J, Scherr A, Tamm M, Stolz D: Vasoactive intestinal peptide for diagnosing exacerbation in chronic obstructive pulmonary disease. Respiration 2015;90:357-368.

7 Vatrella A, Montagnani S, Calabrese C, Parrella R, Pelaia G, Biscione GL, Corcione N, Marsico SA, Guerra G: Neuropeptide expression in the airways of COPD patients and smokers with normal lung function. J Biol Regul Homeost Agents 2010;24:425-432.

$>8$ Lucia P, Caiola S, Coppola A, Manetti LL, Maroccia E, De Martinis C, Buongiorno AM: Vasoactive intestinal peptide in heart failure (in Italian). Ital Heart J Suppl 2000;1:679-685.

$\checkmark 9$ Matucci-Cerinic M, Giacomelli R, Pignone A, Cagnoni ML, Generini S, Casale R, Cipriani P,
Del Rosso A, Tirassa P, Konttinen YT, Kahaleh BM, Fan PS, Paoletti M, Marchesi C, Cagnoni M, Aloe L: Nerve growth factor and neuropeptides circulating levels in systemic sclerosis (scleroderma). Ann Rheum Dis 2001;60:487-494.

10 Lee CM, Kumar RK, Lubowski DZ, Burcher E: Neuropeptides and nerve growth in inflammatory bowel diseases: a quantitative immunohistochemical study. Dig Dis Sci 2002;47: 495-502.

11 Salhy M, Spångéus A: Gastric emptying in animal models of human diabetes: correlation to blood glucose level and gut neuroendocrine peptide content. Ups J Med Sci 2002;107:8999.

12 Umemoto N, Kakurai M, Okazaki H, Kiyosawa T, Demitsu T, Nakagawa H: Serum levels of vasoactive intestinal peptide are elevated in patients with atopic dermatitis. J Dermatol Sci 2003;31:161-164. 